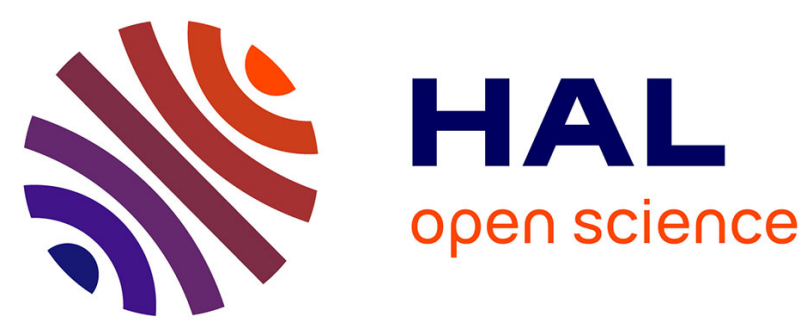

\title{
Why Do Plant Managers Struggle to Synchronize Production Capacity and Costs with Demand in Face of Volatility and Uncertainty?
}

\author{
Manuel Rippel, Johannes Schmiester, Paul Schönsleben
}

\section{To cite this version:}

Manuel Rippel, Johannes Schmiester, Paul Schönsleben. Why Do Plant Managers Struggle to Synchronize Production Capacity and Costs with Demand in Face of Volatility and Uncertainty?. IFIP International Conference on Advances in Production Management Systems (APMS), Sep 2015, Tokyo, Japan. pp.422-430, 10.1007/978-3-319-22756-6_52 . hal-01417523

HAL Id: hal-01417523

https://hal.science/hal-01417523

Submitted on 15 Dec 2016

HAL is a multi-disciplinary open access archive for the deposit and dissemination of scientific research documents, whether they are published or not. The documents may come from teaching and research institutions in France or abroad, or from public or private research centers.
L'archive ouverte pluridisciplinaire HAL, est destinée au dépôt et à la diffusion de documents scientifiques de niveau recherche, publiés ou non, émanant des établissements d'enseignement et de recherche français ou étrangers, des laboratoires publics ou privés. 


\title{
Why do plant managers struggle to synchronize production capacity and costs with demand in face of volatility and uncertainty? - Obstacles within strategizing volume-oriented changeability in practice
}

\author{
Manuel Rippel*, Johannes Schmiester, Paul Schönsleben \\ ETH Zurich, D-MTEC, BWI Center for Industrial Management, Zurich, Switzerland \\ $\{$ mrippel\}@ethz.ch
}

\begin{abstract}
Production plants are currently facing an increase in volatility and uncertainty of demand volumes. This environmental condition comes with highly fixed costs and capacity structures, which are mostly planned on the basis of forecasts and demand projections. Thereby, changing demand causes variances in manufacturing unit costs, endangering production plants' profitability, competitiveness and liquidity. Hence, synchronizing capacities and costs with demand volumes becomes an essential target for plant managers in the face of demand volatility and uncertainty. Approaching this target in practice entails various obstacles due to dynamic and interdependent target conflicts as well as a lack of a dedicated and applicable strategizing approach. In this paper, these obstacles are disclosed and evaluated based on action research cases.
\end{abstract}

Keywords: Uncertainty; Volatility; Resilience; Changeability; Strategizing.

\section{Introduction}

Production plants are currently facing an increasingly volatile and uncertain environment. Demand volatility materializes in fluctuations with shorter cycles and higher amplitudes. Spillovers from a company's market environment (e.g. financial markets, political conflicts, trade embargos) enhance the dynamics behind demand volume fluctuations. Disruptions as a distinct form of volatility due to extreme events are likely to happen more frequently and severely affect companies [1]. These extreme events are highly distinctive in their characteristics making each a one-of-a-kind event [1]. A variety of scientific approaches and concepts have been developed regarding the responsiveness towards changing business environments of organizations and organizational units in the manufacturing sector [2]. There is still no uniform understanding and terminology in academia, neither in one discipline nor cross different disciplines. Instead, several terms (e.g., flexibility, changeability, agility, resilience) are used with partly different, partly overlapping focuses $[3,4,5]$. In addition, technical issues are given priority, and an integration of disciplinary perspectives is mostly left unregarded [2].

adfa, p. 1, 2011.

(C) Springer-Verlag Berlin Heidelberg 2011 
Recently conducted action research cases (in eight production plants in six countries over two years) addressed in depth strategizing and implementing abilities in production plants to handle demand volatility and uncertainty. These cases mainly provide the data for this paper and constitute the basis of the presented findings.

The objective of this paper is to identify and evaluate the obstacles for economically and competitively handling demand volatility and uncertainty in production plants. The purpose is to provide the explicitly revealed problem context for further research on an academically sound and practically relevant approach for strategizing the required abilities of production plants. Therefore, the following reflection questions will be answered by presenting and evaluating the observed and experienced problem context and circumstances in managerial practice:

(a) Which implications have demand volatility and uncertainty on production plants?

(b) Which obstacles arise and hamper managers when dealing with the implications?

\section{Implications of demand volatility and uncertainty}

The first step examines the fundamental issues that arise from the external environmental factors demand volatility and uncertainty and the effect they have on the "production plant." Based on this, a dedicated target is derived and defined.

Volatility is exacerbated by a high degree of uncertainty, making it almost impossible for manufacturing companies to predict future demands and interfering fluctuations and disruptions. In addition, progressing globalization sets requirements for manufacturing companies (e.g. in regard to competitiveness, sourcing and supply chain management) [6]. Production plants face increasing pressure by corporate entities regarding their competitiveness to external peers (e.g. within Make-or-Buy decisions, performance benchmarks). Furthermore, production plants are also exposed to increasing competition in their own manufacturing networks (e.g. within relocation decisions from high-wage to low-wage countries). Demand forecasts and scenarios are often the main basis for planning and decision-making in industrial practice. These forecasts are based either on mathematical extrapolation of historical data or on individual experiences of experts. As the frequency and extent of extreme events increases and are hardly possible to forecast in an uncertain world, their assumptions and recommendations often turn out to be wrong, and plans and decisions regarding capacity structure of production plants fail to materialize.

The above mentioned environmental factors affect capacity structures of manufacturing plants, which are typically characterized by a high level of fixed costs. These structures refer to the main production factors, people, assets and resulting cost positions. Due to their rigid and specific nature, investments into fixed assets can often be regarded as sunk costs, and the related depreciation and financing costs make up a significant share of manufacturing plants' fixed costs [7]. When volatile and uncertain demand markets clash with high levels of rigid fixed costs at the manufacturing plant, high variances of unit costs evolve, which significantly impact the plant's operational performance, i.e. its profitability. Variances of unit costs occur when the antecedent projected unit costs cannot be realized since deviations emerge between forecasted and 
factual production volume. In particular, the fixed cost cannot be absorbed as intended in the forecast. It is not about managing volatility and uncertainty because their occurrence cannot be influenced as external factors. What can be managed is the ability of the system to handle these economic and competitive factors.

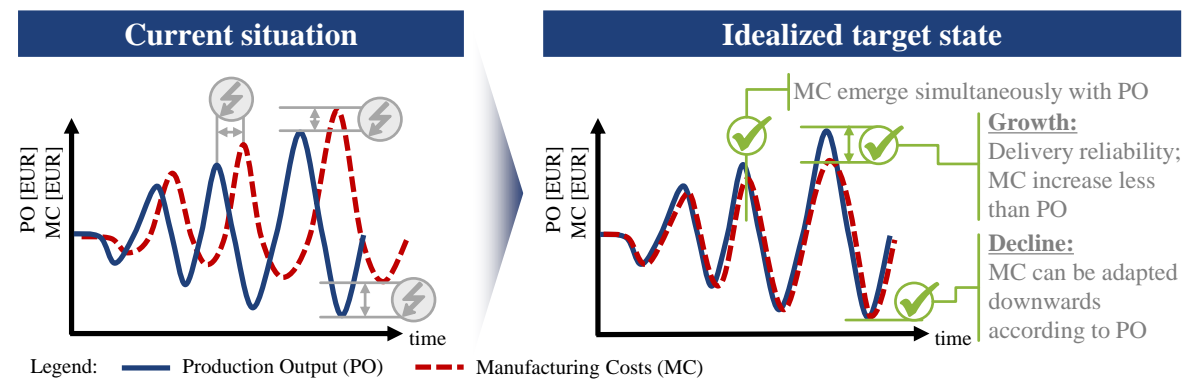

Fig. 1. Volume-oriented changeability - Synchronizing capacity and costs with demand.

Taking these problems into account, a synchronization of capacities and costs with demand volumes becomes an essential target for the production plant management (see Fig. 1). As an idealized target state: Manufacturing costs always emerge simultaneously with the production output as well as with the demanded and appropriately provided capacity. In growth phases, delivery reliability can be ensured while manufacturing costs increase less than production output in order to reduce unit costs and enhance profit margin. In decline phases, manufacturing costs can be adapted downwards according to the descending production output. This kind of synchronization is defined as volume-oriented changeability $(\mathrm{VoC})$, which should ensure robust and sustainable profitability and competitiveness of a production plant [7]. VoC was introduced as concept in order to specifically focus on and address the challenges, obstacles, requirements and solutions of handling the implications of volume fluctuations in industrial practice $[7,8]$. VoC can be regarded as a specific subset of the broad concept of changeability [3] and should contribute to a company's demand-responsive supply chain [9].

\section{Obstacles when dealing with implications}

Dealing with the above mentioned implications involves preventively changing and influencing the system's configuration and characteristics as well as to taking measures when necessary. Plant managers should take action and prepare the plant by strategizing and implementing $\mathrm{VoC}$ with the goal of synchronizing capacities and costs with demand fluctuations. Arising obstacles are identified and evaluated in the following.

\subsection{Business cycle-continuous profitability (O1)}

The intended synchronization of costs and capacities with demand volume is mostly guiding plant managers towards reducing fixed costs and increasing the share of variable costs. Thereby, conflicts evolve in a multi-period perspective (see Fig. 2). 


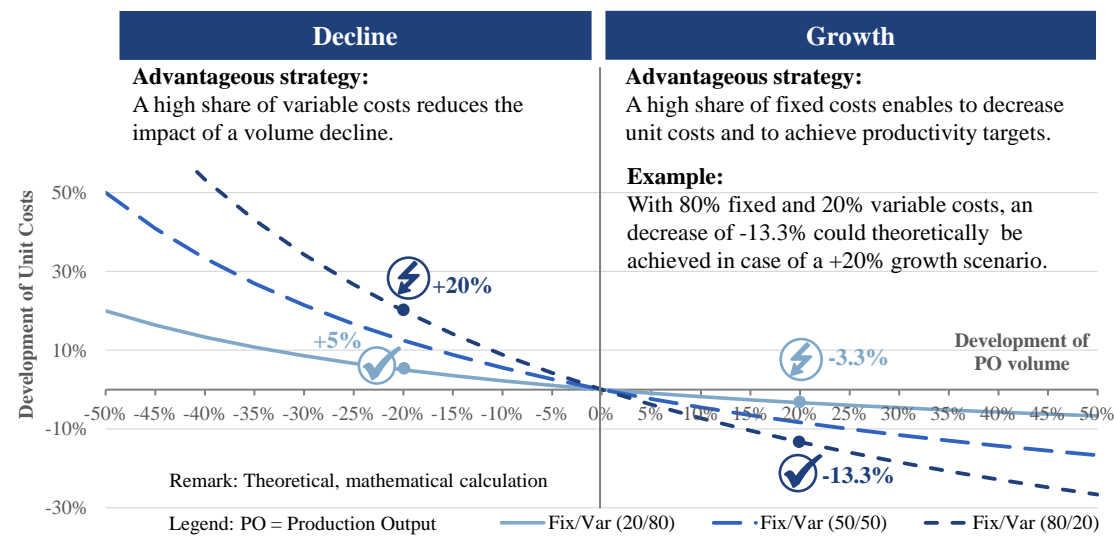

Fig. 2. Development of unit cost dependent on production output and share of fixed costs.

While during decline phases (recession and crisis) variable costs contribute to stabilizing the unit cost level, fixed costs degression effects cannot be realized during growth phases (recovery and expansion). Nevertheless, these effects are requested as an inbuilt contribution to achieve productivity targets. Accordingly, plant managers face the dilemma of choosing diametric-advantageous alternatives for configuring their system: On the one hand, the preventively built-in adjustment abilities would be very advantageous for potential declines since negative impact on the product margin can be mitigated. This strategic orientation requires configuring the production plant with a high percentage of variable costs. On the other hand, the (almost) effortless contribution to productivity targets (and possibly associated personal incentives related to high productivity achievements) is appreciated for potential growth. This approach involves a configuration of the plant's structure with a high percentage of fixed costs.

\subsection{Multi-period competitiveness (O2)}

Several approaches for handling volatility and uncertainty propose a transfer of the inevitable entrepreneurial risks to third parties (e.g. via outsourcing to suppliers, via buyorder-transfer models to service providers or via temporal work to employees). Eventually, this transfer of risks mostly is not for free.

In a socio-technical dimension, transferring the entrepreneurial risk to those third parties might adversely affect among others the innovativeness of the company (e.g. if own know-how gets lost after outsourcing to suppliers), the satisfaction and state of health of employees, or the attractiveness of the production plant as employer. Frequently, these risk premiums cannot be explicitly revealed. The effect is very indirect and elusive since the implications will appear in the long term. Therefore, the extent is often not transparent to the management at the time the decision must be made. In a financial dimension, this external third party might charge this "risk premium" in comparison to proprietary, in-house production. Apparently, it keeps the unit costs (i.e. 
price as allocated costs) constant despite lower quantity of purchased units in comparison to captive production (in particular in the case of cost centers). In the short-term and (probably) in the middle-term, this is possible if the mixed calculation along several periods works and the third party can benefit from an implicit price surcharge ("risk premium") in periods with stable or even higher demand than projected. As a consequence, the plant integrating such external third parties as variable cost might provide a more stable unit cost level due to lower fixed costs but possibly on a higher general level (see Fig. 3). The higher the uncertainty and incalculability, the higher the implicit or explicit risk premium, which continuously arise every period.

Implementation Approach

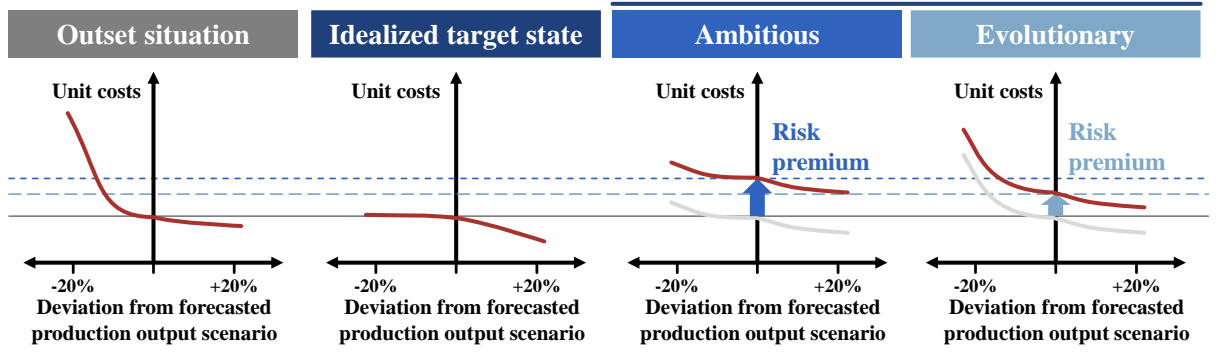

Fig. 3. Unit costs dependent on demand fluctuation and implementation approach (schematic).

Besides, one-time costs within the implementation increase the costs for the ability to synchronize capacity and costs with demand. These (financial and social) costs will depend on the approach to build up the ability. In order to achieve the target sooner than later and to a higher extent ("ambitious" approach), more offensive and proactive measures and significant initial structural adaptations will be required (e.g. to preventively replace employees by temporary workers). In contrast, to achieve the target stepby-step and to a lesser extent ("evolutionary" approach), a combination of proactive and reactive measures are preferred. Initial structural adaptations are restrictively conducted, but every upcoming opportunity to build up VoC is utilized (e.g. if an employee retires, his position is refilled by a temporary worker). The faster and more comprehensive the target is achieved, the more expensive the approach will be.

The financial risk premium can also be non-transparent at times and might be priced unknowingly. Thus, the reverse case can be considered as well. The revealing of implicit price surcharges as well as actively and explicitly discussing risk sharing could be utilized to reduce the price. Nevertheless, the accruing additional costs for the risk premiums for $\mathrm{VoC}$ give rise to the core issue and an inevitable debate on principles between plant and corporate management. How valuable is the adjustment potentials for our company? How much do we want and can we afford to invest in these potentials? The main downside is, when thinking and acting with a focus on isolated single periods, these costs endanger the competiveness of the company (in comparison to competitors) or of the plant (in comparison to external suppliers or other plants, which are less prepared for these scenarios). The benefits might emerge if the accumulated costs over a multitude of periods are compared between both options. Using demand scenarios could even so cause biases due to the inevitable uncertainty. 


\subsection{Multi-dimensional performance $(\mathbf{O 3})$}

The synchronization of costs and capacities with demand volumes implies a variety of target conflicts when applied by practitioners in strategic management of manufacturing plants. At first, the synchronization has implications for other target dimensions and can stand in conflict to these. Other target dimensions affected by the synchronization are technical targets (e.g. capacity and capability targets such as speed, productivity, quality or innovativeness, etc.), financial targets (e.g. cash-flow and profit targets, such as manufacturing costs and liquidity, etc.) and social targets (e.g. employee satisfaction and employer attractiveness consisting of employee motivation, market power on the labor market, etc.) (see Fig. 5) [7, 10]. In these target dimensions, the synchronization can have impacts that can be beneficial or contradicting with existing strategies. For example, buy-order-transfer models can lower the cash outflow but also decrease the ability of the plant to be innovative since the asset is owned and operated by an external party. In addition, these multi-dimensional target conflicts become dynamic since the weighting of the target dimensions varies with the individual above mentioned phases of the business cycles. While during growth delivery reliability might be prioritized, liquidity becomes the main focus during declines. Accordingly, strong dependencies of multi-dimensional performance with the business cycle-continuous profitability (O1) and multi-period competitiveness $(\mathrm{O} 2)$ exist since the target prioritization is subject to temporal aspects. These dynamics of the target conflicts are to be considered when building up structures, during planning processes, and have to be included in performance measurement and assessment tools.

\subsection{Vigorous effectiveness $(\mathrm{O} 4)$}

The obstacle of vigorous effectiveness explicitly describes the degree to which the idealized target state of synchronizing (see chapter 2) can be achieved.

The factor "extent" details how far capacities and respective costs can be adjusted to demand fluctuations and accordingly the extent to which the targeted underlying issue can be solved. The achievable extent strongly depends on the potential to influence the costs by means of appropriate and available levers. The management of fixed costs is an essential element in order to adapt costs to demand fluctuations. Cost remanence as a characteristic of the plant is a main issue which needs to be addressed [11]. The extent of fixed costs is often underestimated since the effective influenceability and particularly the reducibility of the plant's cost structure is over-optimistically estimated. Besides, production plants struggle to adapt their costs in supportive and administrative functions. However, these cost positions should not be neglected since 50\% are bound in support processes, and their cost structure mainly consists of fixed costs [12]. The factor speed characterizes how fast capacities can be adjusted to demand fluctuations. Many companies take action if the market demand and associated production volumes will not evidently recover. Only then do they evaluate, select, and implement measures to adapt capacity. Capacity costs continuously accumulate in doing so, and this cannot be compensated for later on. Interdependencies to $\mathrm{O} 1, \mathrm{O} 2$ and $\mathrm{O} 3$ are apparent. 


\subsection{Practice-oriented Applicability (O5)}

Practitioners have difficulties implementing existing approaches and tools since important requirements might not be given (e.g. data availability, data consistency, data quality) or too laborious to apply so that effort and benefits (e.g. gained knowledge by an analysis) bear no proportion. In addition, some tools are too complex to allow explanation to occasional users or the results to senior management. If many assumptions are necessary and a lot of time and effort required to explain the underlying hypotheses and background fundamentals, various decision makers tend to insufficiently understand and trust the results and consequently reject it as basis for their decision making. However, the opposite trend can also be observed: increasingly gathering and analyzing huge amounts of data, building more complex mathematical models and simulations for decision making. These might help to understand the implications of external factors on the considered system. However, it should be questioned whether quantifying and projecting future risks and their probability of occurrence based on data of the past will lead to reliable results for practitioners in face of uncertainty. In particular, extreme events like black or grey swans [13] can hardly be quantified. Gigerenzer argues that incorrectly assuming to know risks in an uncertain world and using complex calculations and mathematical models for future predictions might result in an illusion of accuracy and certainty within decision making and erroneous beliefs [14].

\begin{tabular}{|c|c|c|c|c|}
\hline \multicolumn{3}{|c|}{ Outset situation } & Approach & Idealized target state \\
\hline Environment & Plant & Implications & & $\begin{array}{l}\text { Synchronizing capacities and } \\
\text { costs with demand volume }\end{array}$ \\
\hline $\begin{array}{l}\text { Volatility } \\
\text { " Fluctuation } \\
\text { " Extreme events } \\
\text { and disruptions } \\
\text { Uncertainty } \\
\text { = Unknown risks } \\
\text { = Unpredictability } \\
\text { Competition } \\
\text { " Dynamics } \\
\text { "Global } \\
\text { comparability }\end{array}$ & $\begin{array}{l}\text { - Capacity structure } \\
\text { with high level of } \\
\text { fixed costs } \\
\text { " Demand planning } \\
\text { and forecasting } \\
\text { based on historical } \\
\text { data, experts, etc. } \\
\text { " Performance } \\
\text { Measurement and } \\
\text { benchmarks } \\
\text { " Relocations and } \\
\text { global sourcing }\end{array}$ & $\begin{array}{l}\text { " Invalid } \\
\text { assumptions and } \\
\text { forecasts } \\
\text { " Under-/Over- } \\
\text { utilization } \\
\text { " Variances of } \\
\text { unit costs } \\
\text { " Profitability and } \\
\text { liquidity } \\
\text { endangered }\end{array}$ & 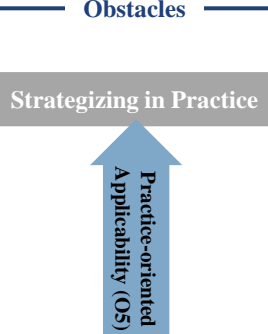 & $\begin{array}{c}\text { usiness cycle-continuous } \\
\text { profitability (O1) } \\
\text { Multi-period } \\
\text { competitiveness (O2) } \\
\text { Multi-dimensional } \\
\text { performance (O3) } \\
\text { Vigorous effectiveness } \\
(\mathrm{O} 4)\end{array}$ \\
\hline
\end{tabular}

Fig. 4. Problem context causing obstacles within achieving VoC-related target.

\section{Conclusion and Outlook}

Based on observations and experiences within action research cases in industrial practice, the implications of demand volatility and uncertainty on production plants are analyzed. Variances of unit costs occur when the antecedent projected unit costs cannot be realized since deviations emerge between forecasted and factual production volume. They significantly impact the plant's operational performance, i.e. its profitability. Therefore, volume-oriented changeability $(\mathrm{VoC})$ sets the target to synchronize production capacity and costs with demand fluctuations. Arising obstacles are identified and evaluated when developing strategies to build up structures in order to synchronize 
costs and capacity with demand volumes in practice. The obstacles can be distinguished in approach-immanent and target-immanent and are summarized in Fig. 4. Based on these obstacles, requirements can be derived for further research on an academically sound and practically relevant approach for strategizing volume-oriented changeability (VoC) as the ability to economically and competitively handle demand volatility and uncertainty in production plants.

\section{$5 \quad$ References}

1. Tainton, J., Nakano, M.: The Behavioural Effects of Extreme Events in Global Supply Chains. In B. Grabot et al. (Eds.): APMS 2014, Part II, IFIP AICT 439, pp. 62-70, (2014)

2. Kampker, A., Burggräf, P., Gartzen, T., Maue, A., Czarlay, D.: Analysis of socio-technical structures in order to increase the changeability of producing companies. Advanced Materials Research Vol. 907, pp. 181-196 (2014)

3. Wiendahl, H.-P., ElMaraghy, H.A., Nyhuis, P., Zäh, M.F., Wiendahl, H.-H., Duffie, N., Brieke, M.: Changeable Manufacturing - Classification, Design and Operation. CIRP Annals - Manufacturing Technology 56 (2), pp. 783-809 (2007)

4. Nyhuis, P., Reinhart, G., Abele, E (eds.).: Wandlungsfähige Produktionssysteme - Heute die Industrie von morgen gestalten. PZH Verlag, Garbsen (2008)

5. Petit, T. J., Fiksel, J., Croxton, K.L.: Ensuring Supply Chain Resilience: Development of a conceptual Framework. Journal of Business Logistics Vol. 31 (1), pp. 1-21 (2010)

6. Koch, S.N.: Methodik zur Steigerung der Wandlungsfähigkeit von Fabriken im Maschinenund Anlagenbau. Dissertation (2012)

7. Rippel, M., Schmiester, J., Wandfluh, M., Schönsleben, P.: Building Blocks for VolumeOriented Changeability of Assets in Production Plants. 48th CIRP Conference on Manufacturing Systems - CIRP CMS (2015) [In press]

8. Rippel, M., Lübkemann, J., Nyhuis, P., Schönsleben, P.: Profiling as a means of implementing volume-oriented changeability in the context of strategic production management. CIRP Annals - Manufacturing Technology 63 (1), pp. 445-448 (2014)

9. Sheffi, Y.: The Resilient Enterprise: Overcoming Vulnerability for Competitive Advantage. MIT Press (2005)

10. Rippel, M., Budde, J.-W., Friemann, F., Schönsleben, P.: Building blocks for volume-oriented changeability in personnel cost structure of manufacturing companies. In B. Grabot et al. (Eds.): APMS 2014, Part II, IFIP AICT 439, pp. 463-470, (2014)

11. Zell, M.: Kosten- und Performance Management - Grundlagen - Instrumente - Fallstudien. Gabler, Wiesbaden (2008)

12. Remer, D.: Einführen der Prozesskostenrechnung: Grundlagen, Methodik, Einführung und Anwendung der verursachungsgerechten Gemeinkostenzurechnung. Schäffer-Poeschel, Stuttgart (2005)

13. Taleb, N.N.: The Black Swan: The Impact of the Highly Improbable, Random House Publishers (2007)

14. Gigerenzer, G: Risk Savvy: How to Make Good Decisions, Viking, New York (2014) 